\title{
Clinical Outcome for Failed Radial Head Arthroplasty Treated with Explantation
}

\author{
David C. Holt, Aimee M. Struk, Joseph J. King, Robert C. Matthias, Thomas W. Wright \\ Department of Orthopaedics and Rehabilitation, University of Florida, Gainesville, USA \\ Email: wrightw@ortho.ufl.edu
}

How to cite this paper: Holt, D.C., Struk, A.M., King, J.J., Matthias, R.C. and Wright, T.W. (2017) Clinical Outcome for Failed Radial Head Arthroplasty Treated with Explantation. Open Journal of Orthopedics, 7, 199-210.

https://doi.org/10.4236/ojo.2017.78022

Received: May 23, 2017

Accepted: July 24, 2017

Published: July 27, 2017

Copyright $\odot 2017$ by authors and Scientific Research Publishing Inc. This work is licensed under the Creative Commons Attribution International License (CC BY 4.0).

http://creativecommons.org/licenses/by/4.0/

\begin{abstract}
Purpose: Failure after radial head arthroplasty is uncommon, but clinically significant. Treatment for failure may involve implant removal. We describe fourteen patients who underwent implant removal after failed radial head arthroplasty. Methods: A retrospective review was performed to determine the cause of failure and clinical data were prospectively collected. Results: At mean follow up of 38 months the mean VAS for pain score was 3.0 and the mean DASH score was 40.5. The mean MEPS was 69. All patients demonstrated improved elbow range of motion. Mean elbow flexion at final follow up was $124^{\circ}$ to an average extension deficit of $25^{\circ}$. Fifty percent of patients exhibited clinical symptoms of cubital tunnel syndrome. Three patients required additional surgery after implant removal. Conclusions: Implant removal for failed radial head arthroplasty improves range of motion and demonstrates acceptable outcomes at intermediate-term follow up. However, $50 \%$ of patients developed cubital tunnel syndrome and $21 \%$ required revision surgery.
\end{abstract}

\section{Keywords}

Clinical Outcome, Cubital Tunnel Syndrome, Explantation, Implant Removal, Radial Head Arthroplasty

\section{Introduction}

Radial head fractures are frequently the result of severe elbow trauma and may be associated with concomitant injury to the collateral ligaments and proximal ulna [1]. The radial head is an important stabilizer of the elbow joint, and instability may develop after radial head fracture. Although it acts as a secondary constraint to valgus stress in a native joint, the radial head becomes a primary stabilizer with associated medial collateral ligament injury [2]. In radial head 
fractures associated with elbow instability, it is important to re-establish longitudinal stability of the forearm via either radial head reconstruction or replacement [3].

Radial head arthroplasty is commonly performed acutely as a treatment for radial head fractures that are not amenable to reconstruction in order to re-establish elbow stability and allow early motion after injury [4]. In addition, radial head arthroplasty is often undertaken to treat the late sequelae of radial head fracture including nonunion, malunion, and/or post-traumatic arthritis. Silicone implants were initially used to replace the radial head; however, concerns regarding implant loosening, silicone synovitis, and late instability have led to a decline in their use [5] [6]. More commonly, metallic implants are used for radial head replacement. Metallic radial head arthroplasty performed for acute fracture of the radial head and neck [3] [7] [8] [9] and for reconstruction after posttraumatic arthritis [10] has demonstrated favorable short-and intermediateterm outcomes.

Complications specific to metallic radial head arthroplasty include stem loosening and capitellar erosion/osteopenia [7] [11] [12] [13] [14] [15]. Failure after radial head arthroplasty can occur for various reasons including pain, stiffness, and instability [13]. Risk factors for failure after radial head arthroplasty include acute unstable fractures, younger patient age, silastic implant, and technical errors in implant placement [13] [16]. Treatment for failed radial head arthroplasty may entail either revision or removal of the implant. To our knowledge, the outcome after failed radial head arthroplasty has not been described in the literature. Therefore, the goal of this study was to describe the clinical outcome after implant removal for failed radial head arthroplasty.

\section{Material and Methods}

Following Institutional Review Board (IRB) approval at our institution, a Current Procedure Terminology search was performed using the code 24,164 (implant removal, radial head). Patients who underwent a removal of radial head arthroplasty from January 1, 1995 through December 31, 2014 were identified. Inclusion criteria were any patient who underwent removal of radial head arthroplasty and was $>18$ years old. Patients who underwent revision radial head arthroplasty (i.e., replacement after removal) or who had follow up of less than 3 months were excluded. Twenty patients were initially identified. Two patients elected not to participate, and an additional 4 patients did not meet the follow-up requirement. Therefore, 14 patients were available for our study. All patients were enrolled either by providing written informed consent or under an approved enrollment waiver granted by the IRB.

The mean follow up was 38 months (3 - 107). Ten females and 4 males were included, with an average age of $51(22-82)$ at the time of implant removal. Two of the radial head implants were silastic, and the remaining 12 were metal. The original diagnoses leading to radial head replacement are listed in Table 1. 
Table 1. Indication for radial head arthroplasty.

\begin{tabular}{cc}
\hline Diagnosis & Number (n) \\
\hline Monteggia Fracture/Dislocation & $7 \%$ \\
Post-Traumatic Arthritis & $14 \%$ \\
Essex-Lopresti Injury & $14 \%$ \\
Isolated Radial Head Fracture & $22 \%$ \\
Terrible Triad Injury & $43 \%$ \\
\hline
\end{tabular}

Patient history and details regarding radial head implant removal were obtained via the electronic medical record. Seven patients underwent isolated radial head arthroplasty. The remaining 7 underwent additional procedures for associated injuries at the time of initial arthroplasty, the details of which are listed in Table 2.

The average time from radial head arthroplasty to subsequent removal was 54 months (6 - 376). Three patients underwent implant removal more than 36 months from the time of arthroplasty $(61,120,376)$. Six patients underwent removal less than 12 months from their initial arthroplasty. Four patients underwent a total of eight additional operations between the initial radial head arthroplasty and eventual implant removal. The indications for radial head implant removal are listed in Table 3. No attempt was made to eliminate data outliers. Missing data were obtained by telephone but in some cases were not available.

Clinical outcome scores including a 10-point visual analog scale for pain (VAS), Mayo Elbow Performance Scores (MEPS), and Disabilities of the Arm, Shoulder, and Hand (DASH) were acquired in person or via telephone interview [17] [18] [19]. The MEPS score rates elbow pain, range of motion, stability, and function on a scale from 0 to 100 . Based on the calculated MEPS score, results were classified as excellent (90 - 100 points), good (75 - 89 points), fair (60 - 74 points), or poor ( $<60$ points). The DASH consists of a 30 -question survey that assesses upper extremity symptom severity and disability on a scale of 0 (no disability) to 100 (complete disability). Because of the small sample size of this patient series statistical analysis was not appropriate.

A goniometer was used to measure elbow range of motion. Grip strength was assessed for both the injured and contralateral extremity using a hand-held dynamometer (TBS 2000 Functional Testing Systems Software, Quest Medical Group, Inc., West Jordan, Utah), and measurements were adjusted based on hand dominance. Flexion and extension of the elbow was measured with the forearm in neutral rotation and pronation and supination was measured with the elbow at $90^{\circ}$ of flexion with the patient holding a dowel. Elbow radiographs were reviewed and degenerative changes were analyzed according to the Broberg and Morrey classification grade 0 (normal joint), grade I (slight joint-space narrowing with minimum osteophyte formation), grade II (moderate joint-space nar- 
Table 2. Patient data.

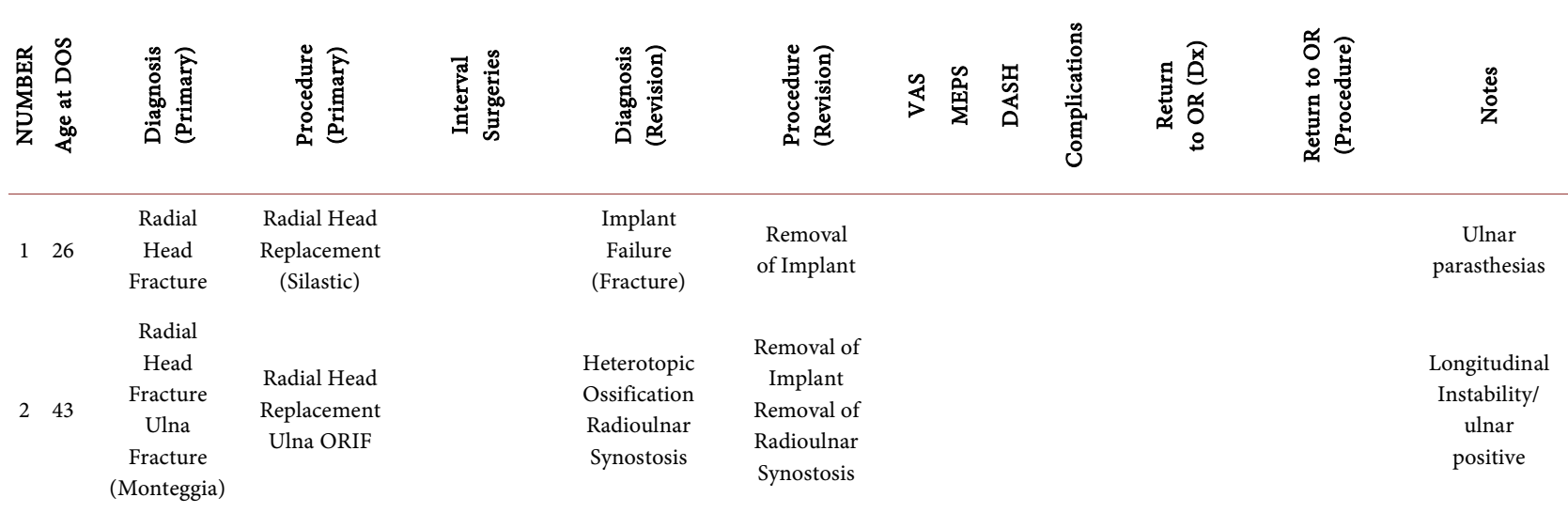

\section{Radial \\ Head \\ 362 Fracture/ Radial Head \\ Dislocation \\ (Terrible Triad)}

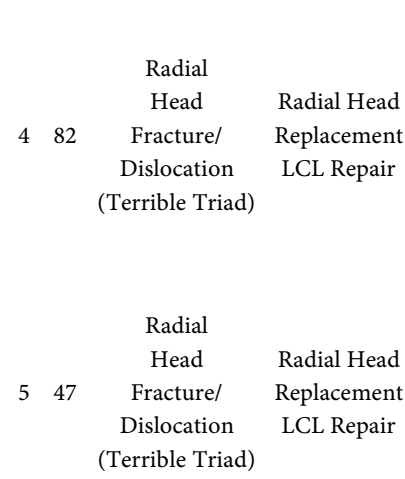

1) Heterotopic

Ossification

Resection

Ulnar Nerve

Transposition

2) Irrigation/

Debridement of

Deep Infection

$\begin{array}{ccccc}\text { Aseptic } & \begin{array}{c}\text { Removal } \\ \text { of Implant }\end{array} & 0 & 100 & 5\end{array}$

No laxity, asymptomatic

$\begin{array}{cc}\text { Removal } \\ \text { Infection } & \text { of Implant } \\ \text { Irrigation and } \\ \text { Debridement }\end{array}$

Removal of

Implant

Contracture

Cubital

Tunnel

Syndrome

Contracture

Release

$1 \quad 75 \quad 60$

Ulnar Nerve

Release in situ
Narcotic

use

Ulnar

paras

thesias

1) External

Fixator

Placement

Coronoid ORIF

$\begin{array}{cc}\text { Radial } & \text { Radial Head } \\ \text { Head } & \text { Replacement }\end{array}$

MCL Repair

$6 \quad 48 \quad$ Fracture/ Coronoid

Dislocation Fracture ORIF (Terrible Triad) LCL Repair

2) Trans

Articular

Pinning

3) Removal of

Implant

Removal of

External Fixator

Elbow

Removal

Contracture

of Implant

Narcotic

use

Ulnar parasthesias

Ulnar parasthesias

Syndrome

Adhesive

Capsulitis

(Shoulder) Implant

Ulnar Nerve

Release in situ

Manipulation

under Anesthesia

(Elbow)

Manipulation

under

Anesthesia

(Shoulder)

Elbow

Contracture

Removal

of Implant

$\begin{array}{lll}0 & 100 & 0\end{array}$

No complaints

Mild objective

valgus laxity 


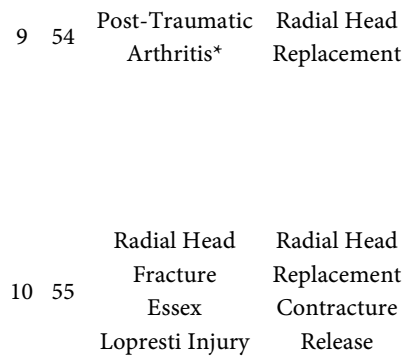

Table 3. Indication for removal of radial head implant

\begin{tabular}{cc} 
Diagnosis & Number (n) \\
Radio-Ulnar Synostosis & $7 \%$ \\
Infection & $7 \%$ \\
Capitellar Arthritis & $7 \%$ \\
Implant Fracture (Silastic) & $14 \%$ \\
Aseptic Loosening & $22 \%$ \\
Elbow Contracture & $43 \%$ \\
\hline
\end{tabular}

rowing with moderate osteophyte formation), or grade III (severe degenerative changes with gross destruction of the joint) [20]. 


\section{Results}

The mean VAS score for pain was $3.0(0$ - 7.6) and the mean DASH score was 40.5 (0 - 86.7). The mean MEPS score was 69 (30 - 100); and based on the MEPS scale two patients had excellent results, three had good results, three had fair results, and two had poor results. All patients demonstrated some improvement in elbow range of motion after radial head implant removal. Mean flexion of the elbow at final follow up was $124^{\circ}$ to an extension deficit of $25^{\circ}$. Pronation of the forearm averaged $72^{\circ}$ and supination averaged $64^{\circ}$. Compared to preoperative assessment, there were improvements in flexion $\left(11^{\circ}\right)$, extension $\left(15^{\circ}\right)$, pronation $\left(8^{\circ}\right)$, and supination $\left(11^{\circ}\right)$. Mean grip strength was $29.8 \mathrm{lbs}$., which represented a $31.2 \%$ deficit compared to the contralateral side when adjusted for hand dominance. The radiographic grade of elbow degeneration based on the Broberg and Morrey classification is shown in Table 4.

Seven of the 14 patients (50\%) complained of paresthesias in the distribution of the ulnar nerve consistent with cubital tunnel syndrome, two of which had previously undergone in situ release at the time of radial head implant removal. One additional patient underwent subsequent ulnar nerve release in situ as a secondary surgery after implant removal. Three patients remained on narcotic medication attributed to their elbow pain, and two patients noted subjective valgus instability of the elbow.

Three patients underwent revision surgery after radial head implant removal during the study period. Patient 9 underwent radial head arthroplasty for posttraumatic arthritis after multiple prior attempts at surgical reconstruction. The patient developed pain and contracture soon after arthroplasty and then subsequently underwent implant removal and contracture release approximately 6 months later. The patient then developed symptoms of proximal radio-ulnar joint impingement and posterior interosseous nerve (PIN) syndrome after implant removal. A proximal radio-ulnar joint reconstruction with allograft interposition and PIN release was performed. At the time of final follow up, the patient had a VAS for pain score of 4 , DASH of 60 , and fair outcome according to the MEPS scale (65).

Patient 11 suffered an Essex-Lopresti-type injury and underwent radial head arthroplasty as part of the initial surgical treatment. Prior to implant removal, a lateral column procedure and removal of heterotopic ossification was performed

Table 4. Broberg and morrey grade.

\begin{tabular}{cc}
\hline Grade & Number (n) \\
\hline O & $7 \%$ \\
I & $58 \%$ \\
II & $14 \%$ \\
III & $7 \%$ \\
N/A & $14 \%$ \\
\hline
\end{tabular}


due to persistent contracture. The radial head implant was then removed approximately 2 years after initial placement. Within 7 months, the patient demonstrated symptoms of longitudinal forearm instability and ulnar positive variance (Figure 1). The patient then underwent ulnar shortening osteotomy with interosseous membrane and distal radio-ulnar joint reconstruction (Figure 2). At final follow up VAS (7.5), DASH (55), and MEPS (60) demonstrated continued pain and a fair outcome.

Patient 9 was a 61-year-old female who sustained a comminuted radial head fracture and elbow dislocation. She was treated with open reduction radial head replacement and ulnar-lateral collateral ligament repair. The radial head subsequently loosened, causing mechanical symptoms and limited range of motion (Figure 3). One year later, the radial head was removed, mechanical symptoms and pain resolved, and final range of motion was $25^{\circ}-140^{\circ}$ flexion to extension and $80^{\circ}$ pronation and supination, respectively (Figure 4 ).

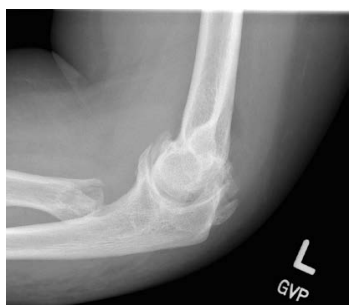

(a)

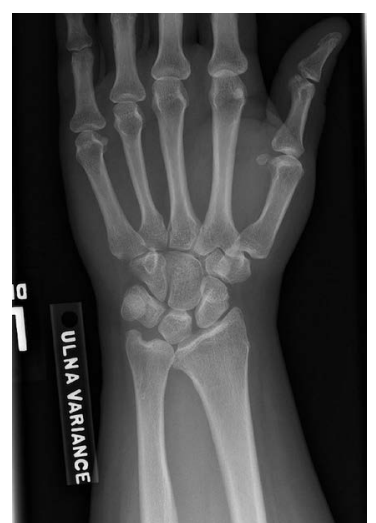

(b)

Figure 1. Lateral radiograph of the elbow (a) and AP radiograph of the wrist (b) demonstrating longitudinal instability of the forearm and positive ulnar variance after removal of the radial head implant in Patient 11.

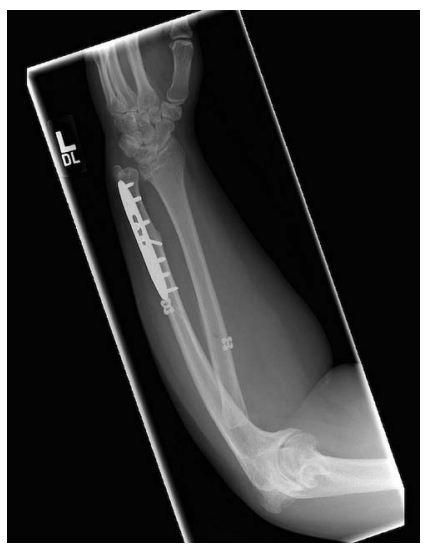

(a)

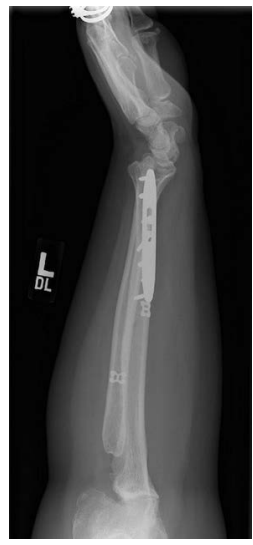

(b)

Figure 2. AP (a) and lateral (b) radiographs of the forearm after ulnar shortening osteotomy and interosseous membrane reconstruction for longitudinal instability of the forearm in Patient 11. 


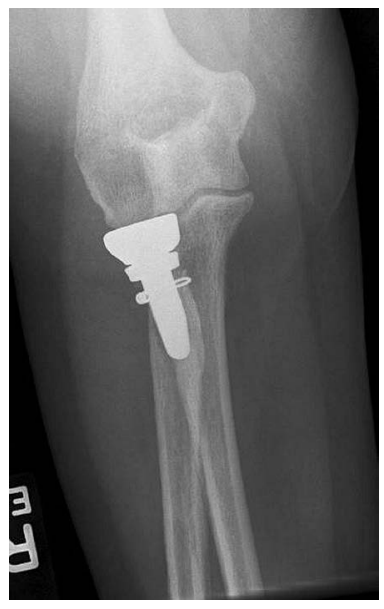

(a)

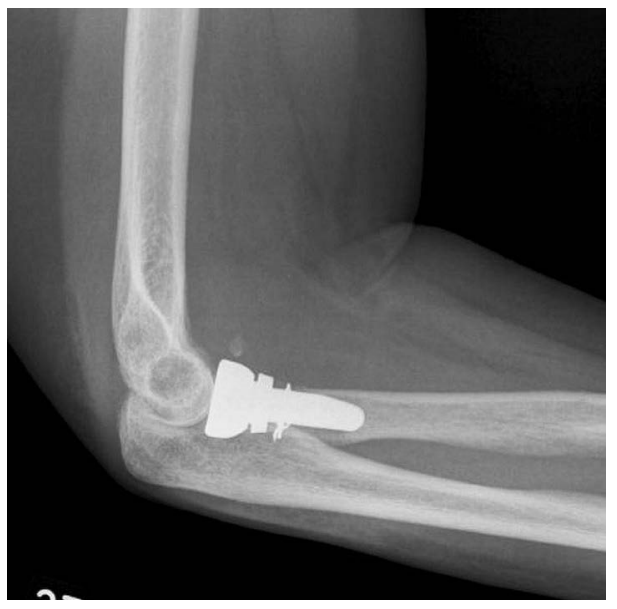

(b)

Figure 3. AP (a) and lateral (b) radiographs of the elbow showing stem loosening of the radial head implant.

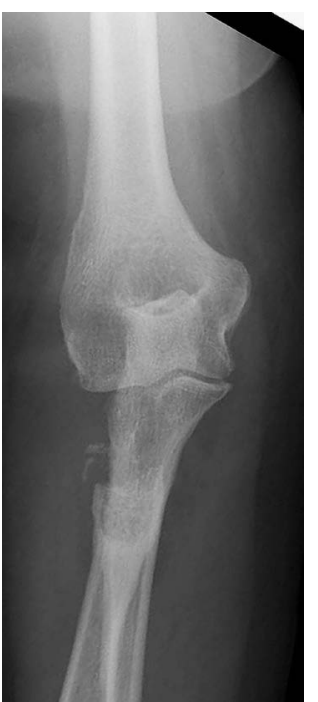

(a)

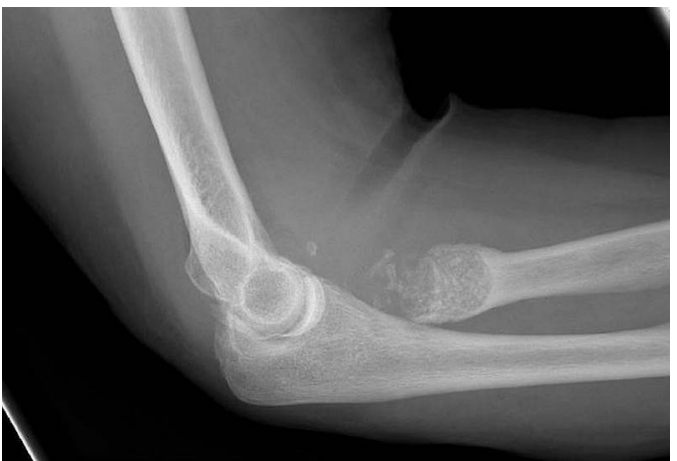

(b)

Figure 4. AP (a) and lateral (b) radiographs of the elbow after explant of the radial head.

Patient 13 required radial head arthroplasty for post-traumatic arthritis after multiple prior attempts at surgical reconstruction. The patient demonstrated signs of implant loosening associated with pain and therefore underwent radial head implant removal. Approximately 18 months later, the patient required ulnar nerve release in situ for persistent complaints of cubital tunnel syndrome. This patient also demonstrated outcome scores below the series average: VAS score of 5, DASH score of 42, and MEPS of 60.

One additional patient underwent radial head implant removal secondary to loosening after arthroplasty due to terrible triad elbow fracture/dislocation. This patient had the poorest outcomes of all patients in the series with a VAS score of 6.7, a DASH score of 87, and an MEPS of 30, all consistent with significant pain and disability. Because of the development of post-traumatic arthritis the patient 
was scheduled for a total elbow arthroplasty at the time of final follow up for this study.

\section{Discussion}

To our knowledge, this study is the first to describe the outcome of patients undergoing implant removal after failed radial head arthroplasty. In a small number of patients, we have demonstrated acceptable outcomes in the majority of patients. Several of the patients in this series reported minimal pain and dysfunction, while several others demonstrated continued significant disability. All patients attained improvement in elbow range of motion after radial head implant removal, and the average flexion to extension deficit $\left(124^{\circ}-25^{\circ}\right)$ attained closely corresponds to the accepted $100^{\circ}$ functional arc of motion from $30^{\circ}$ $100^{\circ}$ of flexion [21].

Three patients required revision surgery after radial head implant removal, and a fourth patient remained severely disabled and was scheduled to undergo total elbow arthroplasty at the conclusion of the study. Each of these patients had undergone multiple surgical procedures prior to radial head implant removal, likely indicative of significant underlying disability and more severe elbow injury. Additionally, two patients in this study underwent radial head replacement for post-traumatic arthritis, and both of these patients are included in the above-noted failures. Two of the patients in this study underwent radial head arthroplasty due to an Essex-Lopresti injury. Both of these patients also required revision surgery after implant removal consistent with the severe nature of the original injury. One of these patients developed longitudinal instability of the forearm after implant removal, which is suggestive of underlying instability that had been masked by the radial head arthroplasty.

Of note, a high percentage of the patients in the study demonstrated symptoms consistent with cubital tunnel syndrome. We believe this is likely related to persistent valgus instability of the elbow, which may be imperceptible to the patient and rarely led to frank symptomatic instability of the elbow but was significant enough to irritate the ulnar nerve.

While no previous studies have described outcomes after removal of failed radial head arthroplasty, short-to intermediate-term follow up after arthroplasty for radial head fracture has generally demonstrated favorable results [3] [7] [8] [9] [16]. Risk factors for failure after radial head arthroplasty include acute unstable fractures, younger patient age, silastic implant, and technical errors in implant placement such as overstuffing [13] [16]. Surgical options for failed radial head arthroplasty generally involve revision versus implant removal.

Removal of a radial head implant may be compared to radial head excision for primary and delayed treatment for radial head fractures. Multiple studies have demonstrated excellent long-term results after radial head excision [20] [22] [23] [24]. Concerns over valgus instability and proximal migration of the radius persist; therefore, intraoperative assessment of longitudinal instability via a push-pull test has been recommended [25]. 
One of the main limitations of this study is that a single cohort of patients was available for review with no control or comparative group. In addition, we reviewed a heterogeneous group of patients who underwent radial head arthroplasty for a variety of both acute and chronic elbow pathology. However, the strength of the study lies in the fact that this group of patients had not previously been described in the literature.

In this study, the majority of patients demonstrated fair to good outcomes after removal of failed radial head arthoplasty. All patients attained improved range of motion. A high percentage of patients exhibited persistent signs of cubital tunnel syndrome, and one of our patients developed longitudinal instability of the forearm after implant removal. Though limited by the number of patients in this study, worse outcomes were demonstrated in patients undergoing implant removal after radial head arthroplasty for post-traumatic arthritis or Essex-Lopresti injury.

In conclusion, implant removal is a viable treatment option for failed radial head arthroplasty. We advise giving strong consideration to ulnar nerve release with transposition after radial head implant removal. In addition, intraoperative assessment of longitudinal stability after implant removal is imperative and should be corrected as indicated.

\section{References}

[1] Van Riet, R.P., Morrey, B.F., O’Driscoll, S.W. and Van Glabbeek, F. (2005) Associated Injuries Complicating Radial Head Fractures: A Demographic Study. Clinical Orthopaedics and Related Research, 441, 351-355. https://doi.org/10.1097/01.blo.0000180606.30981.78

[2] Regan, W.D., Korinek, S.L., Morrey, B.F. and An, K.N. (1991) Biomechanical Study of Ligaments Around the Elbow Joint. Clinical Orthopaedics and Related Research, 271, 170-179. https://doi.org/10.1097/00003086-199110000-00023

[3] Harrington, I.J., Sekyi-Otu, A., Barrington, T.W., Evans, D.C. and Tuli, V. (2001) The Functional Outcome with Metallic Radial Head Implants in the Treatment of Unstable Elbow Fractures: A Long-Term Review. Journal of Trauma, 50, 46-52. https://doi.org/10.1097/00005373-200101000-00009

[4] Al-Burdeni, S., Abuodeh, Y., Ibrahim, T. and Ahmed, G. (2015) Open Reduction and Internal Fixation versus Radial Head Arthroplasty in the Treatment of Adult Closed Comminuted Radial Head Fractures (Modified Mason type III and IV). International Orthopaedics, 39, 1659-1664.

https://doi.org/10.1007/s00264-015-2755-1

[5] Morrey, B.F., Askew, L. and Chao, E.Y. (1981) Silastic Prosthetic Replacement for the Radial Head. The Journal of Bone and Joint Surgery, 63, 454-458. https://doi.org/10.2106/00004623-198163030-00021

[6] Vanderwilde, R.S., Morrey, B.F., Melberg, M.W. and Vinh, T.N. (1994) Inflammatory Arthritis after Failure of Silicone Rubber Replacement of the Radial Head. The Journal of Bone and Joint Surgery, 76, 78-81.

[7] Moro, J.K., Werier, J., MacDermid, J.C., Patterson, S.D. and King, G.J. (2001) Arthroplasty with a Metal Radial Head for Unreconstructible Fractures of the Radial Head. The Journal of Bone and Joint Surgery, 83, 1201-1211. 
https://doi.org/10.2106/00004623-200108000-00010

[8] Grewal, R., MacDermid, J.C., Faber, K.J., Drosdowech, D.S. and King, G.J.W. (2006) Comminuted Radial Head Fractures Treated with a Modular Metallic Radial Head Arthroplasty. Study of Outcomes. The Journal of Bone and Joint Surgery, 88, 21922200.

[9] Ashwood, N., Bain, G.I. and Unni, R. (2004) Management of Mason Type-III Radial Head Fractures with a Titanium Prosthesis, Ligament Repair, and Early Mobilization. The Journal of Bone and Joint Surgery, 86, 274-280. https://doi.org/10.2106/00004623-200402000-00009

[10] Shore, B.J., Mozzon, J.B., MacDermid, J.C., Faber, K.J. and King, G.J. (2008) Chronic Post-traumatic Elbow Disorders Treated with Metallic Radial Head Arthroplasty. The Journal of Bone and Joint Surgery, 90, 271-280.

https://doi.org/10.2106/JBJS.F.01535

[11] Fehringer, E.V., Burns, E.M., Knierim, A., Sun, J., Apker, K.A. and Berg, R.E. (2009) Radiolucenies Surrounding a Smooth-Stemmed Radial Head Radial Head Component May Not Correlate with Forearm Pain or Poor Elbow Function. Journal of Shoulder and Elbow Surgery, 18, 275-278.

[12] O’Driscoll, S.W. and Herald, J.A. (2012) Forearm Pain Associated with Loose Radial Head Prosthesis. Journal of Shoulder and Elbow Surgery, 21, 92-97.

[13] Van Riet, R.P., Sanchez-Sotelo, J. and Morrey, B.F. (2010) Failure of Metal Radial Head Replacement. The Journal of Bone and Joint Surgery, 92, 661-667. https://doi.org/10.1302/0301-620X.92B5.23067

[14] Kang, S.H., Kim, D.Y., Park, H. and Song, H.S. (2015) Anthropometric Study of the Proximal Radius: Does Radial Head Implant Fit in all Cases? International Orthopaedics, 39, 1553-1561. https://doi.org/10.1007/s00264-015-2773-Z

[15] Delclaux, S., Lebon, J., Faraud, A., Toulemonde, J., Bonnevialle, N., Coulet, B. and Mansat, P. (2015) Complications of Radial Head Prostheses. International Orthopaedics, 39, 907-913. https://doi.org/10.1007/s00264-015-2689-7

[16] Duckworth, A.D., Wickramasinghe, N.R., Clement, N.D., Court-Brown, C.M. and McQueen, M.M. (2014) Radial Head Replacement for Acute Complex Fractures: What Are the Rate and Risks Factors for Revision or Removal? Clinical Orthopaedics and Related Research, 472, 2136-2143. https://doi.org/10.1007/s11999-014-3516-y

[17] Morrey, B.F. and An, K.N. (2000) Functional Evaluation of the Elbow. In: Morrey, B.F., Ed., The Elbow and Its Disorders, 3rd Edition, WB Saunders, Philadelphia, 82.

[18] Hudak, P., Amadio, P.C., Bombardier, C. and the Upper Extremity Collaborative Group (1996) Development of an Upper Extremity Outcome Measure: The DASH (Disabilities of the Arm, Shoulder, and Hand). American Journal of Industrial Medicine, 29, 602-608.

https://doi.org/10.1002/(SICI)1097-0274(199606)29:6<602::AID-AJIM4>3.0.CO;2-L

[19] Kennedy, C.A., Beaton, D.E., Solway, S., McConnell, S. and Bombardier, C. (2011) Disabilities of the Arm, Shoulder and Hand (DASH). The DASH and Quick DASH Outcome Measure User's Manual, 3rd Edition, Institute for Work \& Health, Toronto.

[20] Broberg, M.A. and Morrey, B.F. (1986) Results of Delayed Excision of the Radial Head after Fracture. The Journal of Bone and Joint Surgery, 68, 669-674. https://doi.org/10.2106/00004623-198668050-00005

[21] Morrey, B.F., Askew, L. and Chao, E.Y. (1981) A Biomechanical Study of Normal Functional Elbow Motion. The Journal of Bone and Joint Surgery, 63, 872-877. 
https://doi.org/10.2106/00004623-198163060-00002

[22] Iftimie, P.P., Calmet Garcia, J., de Loyola Garcia Forcada, I., Gonzalez Pedrouzo, J.E. and Giné Gomà, J. (2011) Resection Arthroplasty for Radial Head Fractures: Long-Term Follow-Up. Journal of Shoulder and Elbow Surgery, 20, 45-50.

[23] Antuña, S.A., Sánchez-Márquez, J.M. and Barco, R. (2010) Long-Term Results of Radial Head Resection Following Isolated Radial Head Fractures in Patients Younger than Forty Years Old. The Journal of Bone and Joint Surgery, 92, 558-566. https://doi.org/10.2106/JBJS.I.00332

[24] Herbertsson, P., Josefsson, P.-O., Hasserius, R., Besjakov, J., Nyqvist, F. and Karlsson, M.K. (2004) Fractures of the Radial Head and Neck Treated with Radial Head Excision. The Journal of Bone and Joint Surgery, 86, 1925-1930.

https://doi.org/10.2106/00004623-200409000-00010

[25] Smith, A.M., Urbanosky, L.R., Castle, J.A., Rushing, J.T. and Ruch, D.S. (2002) Radius Pull Test: Predictor of Longitudinal Forearm Instability. The Journal of Bone and Joint Surgery, 84, 1970-1976.

https://doi.org/10.2106/00004623-200211000-00010

Scientific Research Publishing

\section{Submit or recommend next manuscript to SCIRP and we will provide best} service for you:

Accepting pre-submission inquiries through Email, Facebook, LinkedIn, Twitter, etc. A wide selection of journals (inclusive of 9 subjects, more than 200 journals)

Providing 24-hour high-quality service

User-friendly online submission system

Fair and swift peer-review system

Efficient typesetting and proofreading procedure

Display of the result of downloads and visits, as well as the number of cited articles

Maximum dissemination of your research work

Submit your manuscript at: http://papersubmission.scirp.org/

Or contact ojo@scirp.org 